\section{Scope for New}

\section{Applications for \\ Gold Arising from}

the Electrocatalytic Behaviour of its

\section{Metastable Surface States}

\section{Laurence D. Burke}

Chemistry Department, University College Cork, Cork, Ireland

The electrocatalytic behaviour of gold in aqueous media is surprisingly complex and a novel view of gold electrode surfaces is proposed to explain the observed electrochemical responses. The metal surface is considered as a chemically (or redox) modified electrode, with equilibrated, low energy, surface gold atoms functioning as a relatively inert support and low coverage, high energy, protruding gold atoms (or minute clusters of same) functioning as electrocatalytic redox mediators. The protruding atoms are viewed as surface active sites and the complex electrocatalytic behaviour is attributed to the basic instability of the mediators, the diversity (and poor control) of same, and the acid/base (or hydrolysis) behaviour of the oxidized states of the mediators. It is assumed that major advances in the application of gold in the heterogeneous catalysis of gas phase reactions will be accompanied by similar advances in the use of gold in the electrocatalysis area; however, this will require considerable work of both a practical and theoretical nature.

\section{Introduction}

Gold is the noblest of metals (1), i.e. its surface is remarkably resistant to oxidation. The metal is a very weak chemisorber and was traditionally regarded, in terms of the activated chemisorption theory (2), as a very poor catalyst or electrocatalyst. However, it has been known for quite some time that even macroscopic gold displays remarkable electrocatalytic activity, especially in base, for certain Faradaic processes, e.g. aldehyde oxidation (3); a 2-part review of the electrocatalytic properties of gold in aqueous media was published recently $(4,5)$. The unexpectedly high catalytic behaviour of gold surfaces was highlighted by Haruta and co-workers (6) who observed that oxidesupported gold nanoparticles display unrivalled catalytic activity for certain processes such as carbon monoxide oxidation. The investigation of gold nanoparticles in the heterogeneous catalysis area is now an extensive area of research (7) which will not be described here.

The linkage between the electrocatalytic properties of macroscopic gold and the catalytic properties of gold nanoparticles seems to be that in both cases metastable (or high energy) surface gold atoms are involved. Metastability (or non-equilibrium states) is the essence of metallurgy $(8,9)$ and it is surprising that this factor has been largely ignored in the surface electrochemistry of the noble metals. There are practical reasons for this, e.g. (i) metastable states are disordered and are difficult to generate in a reproducible manner; also these states tend to alter with pretreatment, time and use, (ii) the surface energy of a solid is not a readily measurable quantity (10), (iii) techniques for investigating low coverage, mobile species, especially at disordered surfaces, are quite limited (11). In the present case it is convenient to adopt the notation used by Spencer (12) who classified the surfaces of small metal particles into two types: (a) Equilibrated (low energy) Metal Surfaces (EMS), and (b) Metastable (high energy) Metal Surfaces (MMS). MMS states appear to be the basis of surface active site behaviour.

\section{Surface Active Sites}

The concept of the surface active site was introduced by Taylor (13) in 1925. He postulated that only a very small percentage of surface atoms participated in surface catalysed reactions. Since heat treatment of the sample led to loss of catalytic activity, he assumed that active sites consisted of poorly crystallized, i.e. metastable, material. As is clear from Fig. 1 in Taylor's paper, a catalytic surface may be regarded as a layer of EMS atoms (well embedded in the lattice surface) coated with a low coverage of MMS (protruding) atoms. He also stressed that protruding atoms 


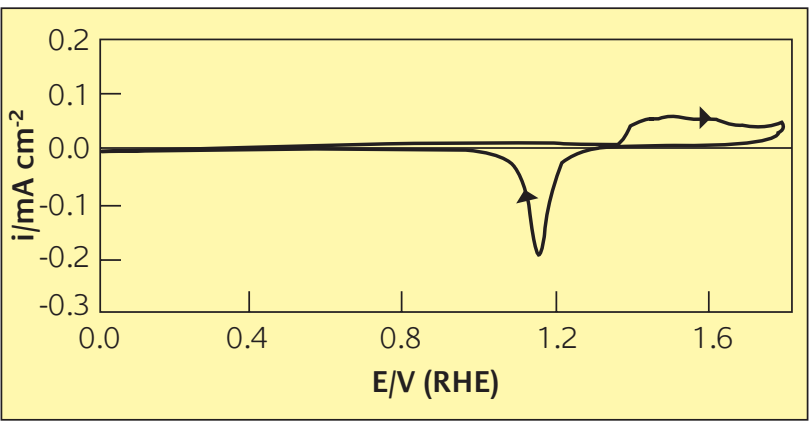

Figure 1:

Cyclic voltammogram (0.0-1.8 $\left.\mathrm{V}, 50 \mathrm{mV} \mathrm{s}^{-1}\right)$ for an unactivated gold electrode surface in $1.0 \mathrm{~mol} \mathrm{dm}^{-3} \mathrm{H}_{2} \mathrm{SO}_{4}$ at $25^{\circ} \mathrm{C}$ (33)

(which have a low lattice stabilization energy) are high energy species, pointing out that the enthalpy of adsorption of oxygen on charcoal under high temperature, low coverage, conditions exceeded the standard enthalpy of formation of gaseous carbon dioxide by a factor of ca. 2.3 (the protruding carbon atoms involved in the chemisorption under these conditions being high energy, semi-gaseous species). In essence, it appears that, for the same surface, the properties of MMS and EMS atoms are quite different. Support for Taylor's view was provided recently by Somorjai (11) who stressed that surface roughness (or disorder) is vital for high catalytic activity, e.g. reactions occur at stepped surfaces under much milder conditions than on terraces. A further complexity of active site behaviour, mentioned by Taylor (13), is that the protruding (MMS) atoms are not equivalent, i.e. there are different types of active sites which catalyse different reactions, often apparently in a rather selective manner.

\section{Metal Microcluster Behaviour}

An active metal catalyst may be regarded as microclusters of metal atoms, which are in the MMS state and function as active sites, resting on terrace atoms which are in the EMS state and function as a support for the active sites (interactions between the cluster and terrace atoms are ignored here). The atoms in the microcluster are in a high energy state as their lattice stabilization energy is low and their conduction electrons experience quantum confinement effects. The electrochemical properties of metal microclusters in aqueous media were reviewed by Henglein (14) who pointed out that atoms in this state are (a) highly reactive (the clusters tended to agglomerate quite readily) and (b) unusually electropositive. In the case of silver, the removal of a silver atom from the metal lattice resulted in a change in redox potential $\left(E^{\circ}\right)$ from ca. +0.8 $\mathrm{V}(\mathrm{SHE})$ to ca. $-1.8 \mathrm{~V}(\mathrm{SHE})$. The shift in potential (reflecting an increase in atomic energy) was most dramatic for very small cluster sizes; however, the trend in this area was complicated by magic number behaviour, i.e. certain cluster sizes, e.g. $\mathrm{Ag}_{2}$ and $\mathrm{Ag}_{8}$, were found to be abnormally stable (with regard to both agglomeration and oxidation; however, all clusters are more active than the bulk metal). High energy surface clusters, e.g. individual metal atoms, are quite unstable; however, they may exist at the surface as transient species formed for instance in the course of surface atom migration between defect sites (their coverage may be enhanced in the course of energyreleasing catalytic processes).

Interesting confirmation of the fact that the electronic properties of a metal surface are affected by disorder has been provided by Besocke and Wagner (15). They observed that evaporating tungsten atoms onto a tungsten single crystal surface lowered the work function of the latter by up to $0.6 \mathrm{eV}$. Annealing the sample at $700^{\circ} \mathrm{C}$ resulted in the reordering of the adatom layer and the work function returned to its original value.

\section{Oxidation of Surface Metal Clusters}

Due to their electropositive character, protruding active site metal atoms undergo oxidation at unusually low potentials, i.e. within the so-called double layer region in aqueous media. This phenomenon, referred to as premonolayer oxidation, is a controversial topic for a variety of reasons. Theories of double layer behaviour, based largely on data obtained with liquid metal electrodes (usually mercury), generally ignore MMS states which arise only with solid electrodes. Earlier claims of Faradaic responses within the double layer region for gold were attributed to the presence of impurities (1). However, Surface Enhanced Raman Spectroscopy (SERS) data for gold (16), silver (17) and copper (18) electrodes in base have established that hydroxy species are produced at the metal/solution interface at potentials well into the double layer region. Also, in the case of gold in base (16), the product formed in premonolayer oxidation differs (on the basis of its SERS response) from the conventional monolayer oxide film (formed on oxidation of EMS gold atoms).

The product of premonolayer oxidation of gold is often regarded as an adsorbed hydroxyl radical, $\mathrm{OH}_{\text {ads. }}$. However, this is improbable as the hydroxyl radical is a high energy (or very electronegative) species, $E^{\circ}\left(\mathrm{H}_{2} \mathrm{O} / \mathrm{OH}\right)=2.85 \mathrm{~V}(\mathrm{SHE})$ (19), and adsorption on gold is unlikely to provide much stability. The species that are most likely to undergo oxidation at the interface at low potentials are MMS gold atoms ( $\mathrm{Au}^{*}$ ), the resulting cations then combining with hydroxide ions to form metal hydroxy complexes, viz. 


$$
\mathrm{Au}^{*}-\mathrm{e}^{-} \rightarrow \mathrm{Au}^{+} \text {ads }\left(+\mathrm{OH}^{-}\right) \rightarrow \mathrm{AuOH}_{\text {ads }}
$$

The reaction at the interface is more complex than suggested by this equation and the following factors should be borne in mind, viz.

(i) MMS atoms are protruding species so that the cations formed can also coordinate water molecules, i.e. the product is likely to be a hydrous (or $\beta$ ) oxide, rather than the usual monolayer (or $\alpha$ ) oxide or hydroxide. Just as there are two types of surface metal atoms (EMS and MMS), there are also two basic types of surface oxide species ( $\alpha$ and $\beta$ ). The $\beta$ oxides can be produced in multilayer form (20); they tend to be poorly ordered, low density materials which undergo reduction in a negative voltammetric sweep only at low potentials as apparently the initial reduction product is the MMS state of the metal $\left(A u^{*}\right)$.

(ii) Gold has two common oxidations states, I and III (21). Hence, there are two possible ( $\beta$ oxide) oxidation products, $\mathrm{AuOH}$ (whose existence in bulk form is dubious but may exist as an intermediate) and $\mathrm{Au}(\mathrm{OH})_{3}$ or $\mathrm{Au}_{2} \mathrm{O}_{3} \cdot 3 \mathrm{H}_{2} \mathrm{O}$. Reduction of multilayer $\mathrm{Au}(\mathrm{III})$ oxide films often yields a range of cathodic peaks (22); the reason for this is uncertain, it may be due to variations in oxide film density, foreign ion content of the film or the activity of the initial metal atoms formed on reduction (these factors may be interrelated).

(iii) Metal hydroxides exhibit acid-base (or hydrolysis) behaviour (20) which affects both their redox and their electrocatalytic properties. AuOHads is assumed (like $\mathrm{NaOH}$ ) to be a strong base, i.e. it apparently exists at the interface largely in a cationic form, $\mathrm{Au}^{+}\left(\mathrm{H}_{2} \mathrm{O}\right)_{n, \text { ads }}$, and this species tends to mediate reactions in which the dissolved reactant is anionic, i.e. the formation of the mediator $\left(\mathrm{Au}^{+}\right) /$reactant $\left(\mathrm{X}^{-}\right) \quad$ complex involves electrostatic attraction forces. The $\mathrm{Au}(\mathrm{III})$ hydroxide apparently behaves as an acid, i.e. it tends to accept, rather than donate, hydroxide ions (due to the high charge on the $\mathrm{Au}^{3+}$ cation) and the species formed at the interface has been formulated (20) as $\left(\mathrm{Au}_{2}(\mathrm{OH})_{9}\right]^{3-}$ ads. Such a formulation is not uncommon (23); it is found in several halides, e.g. $\left(\mathrm{Cr}_{2} \mathrm{Cl}_{9}\right]^{3-}$ and $\left(\mathrm{Bi}_{2} \mathrm{Br}_{9}\right]^{3-}$, and involves face-sharing octahedra which, on continued linking of the latter, yield low density strand structures of composition $\mathrm{MX}_{3}$, i.e. the extended structure may be uncharged but the segment of same undergoing reaction in oxide reduction or electrocatalytic processes is apparently anionic. The anionic character of the Au(III) hydroxide is important with regard to super-Nernstian $\mathrm{E} / \mathrm{pH}$ behaviour (20); it results in a negative shift in redox potential with increasing solution $\mathrm{pH}$ and seems to be reason why many electrocatalytic processes commence at a lower potential on gold in base as compared with acid (24).

In summary, it seems that gold oxide behaviour is at least as complex as that of the active metal. With regard to electrocatalysis, the uncertainties concerning the nature of the vital mediator species, and the difficulty of deriving analytical data for these very low coverage, rather labile entities, inevitably means that detailed mechanisms of electrocatalytic processes at gold are currently rather speculative.

\section{The Electrochemistry of EMS Gold}

A conventional cyclic voltammogram for gold in acid solution is shown in Fig. 1. The $\alpha$ oxide, nominally $\mathrm{Au}_{2} \mathrm{O}_{3}$, formation response commences at ca. $1.36 \mathrm{~V}$ in the positive sweep and this deposit is reduced back to the metal at ca. $1.15 \mathrm{~V}$ (the potential scale used in this article, unless designated otherwise, is RHE, i.e. hydrogen, at $1 \mathrm{~atm}$, in the same solution). Such behaviour has been discussed in detail earlier $(1,25)$ but a few points are worth noting. The onset potential is close to the $\mathrm{E}^{\circ}$ values (26) for $\mathrm{Au}_{2} \mathrm{O}_{3}, 1.511 \mathrm{~V}(\mathrm{SHE})$, and $\mathrm{Au}(\mathrm{OH})_{3}, 1.457 \mathrm{~V}(\mathrm{SHE})$, formation (for $1.0 \mathrm{~mol} \mathrm{dm}^{-3}$ strong acid solution the RHE and SHE scale virtually coincide); the slightly lower value for the start of monolayer oxidation suggests that the EMS gold atoms are somewhat more active (as expected) than their bulk equivalent. The double layer region (0.0 to ca. $1.35 \mathrm{~V}$, positive sweep) is featureless, apart from the non-Faradaic current flow. The absence of an adsorbed hydrogen response, compared with platinum (1), confirms the weak chemisorbing power of EMS gold and there is no obvious indication of an $\mathrm{Au} / \mathrm{AuOH}$ transition (it is assumed (27) that the latter occurs well prior to $\mathrm{Au}_{2} \mathrm{O}_{3}$ formation).

\section{The Electrochemistry of MMS Gold}

Although one may define a specific MMS state, e.g. in terms of a stepped single crystal surface, the degree of disorder associated with very high energy surfaces implies that these states (and their electrochemical responses) are variable (or history-dependent). It seems that in former times the generation of MMS states of gold was carried out in some occasions inadvertently, e.g. when the gold wire was heated in forming a glass/metal seal or when the electrode surface was abraded. This may account for instance for the slight arrest in the anodic charging curves just above $1.0 \mathrm{~V}$ (prior to the more extended arrest at ca. $1.36 \mathrm{~V}$ ) reported much earlier for gold in acid by Vetter and Berndt (28) (this premonolayer oxidation feature at ca. $1.0 \mathrm{~V}$ was discussed 


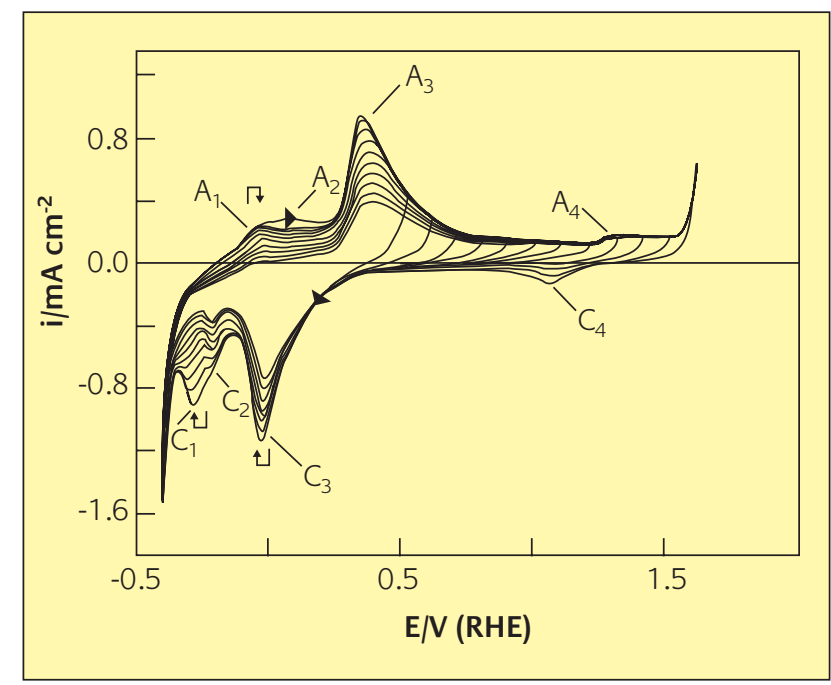

Figure 2:

Cyclic voltammograms $\left(50 \mathrm{mV} \mathrm{s}^{-1}\right)$ for a cooled bead gold electrode in $1.0 \mathrm{~mol} \mathrm{dm}{ }^{-3} \mathrm{NaOH}$ at $25^{\circ} \mathrm{C}$. The lower limit was $-0.4 \mathrm{~V}$; the upper limit was increased upwards, in steps of $0.1 \mathrm{~V}$, from $0.5 \mathrm{~V}$. The arrows indicate the direction of change in peak height (36)

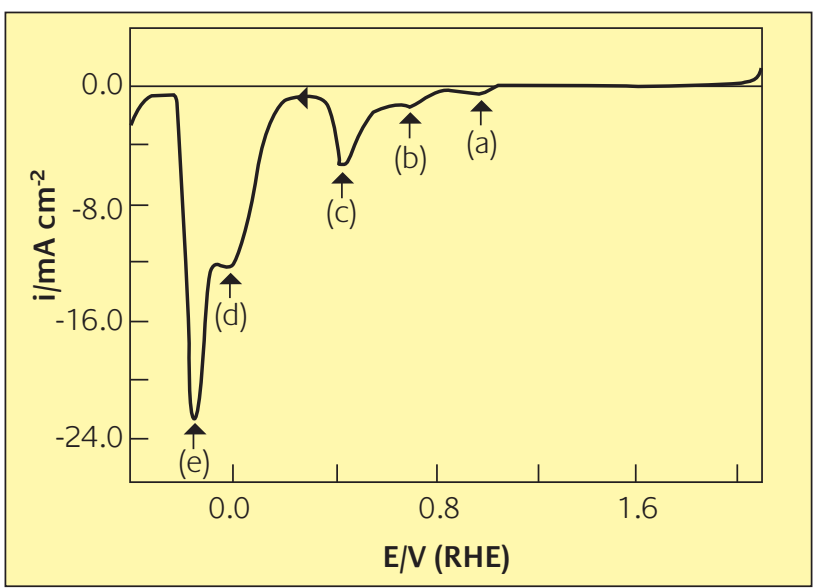

Figure 3:

Reduction sweep $\left(2.1 \rightarrow-0.4 \mathrm{~V}, 10 \mathrm{mV} \mathrm{s}^{-1}\right)$ for a multilayer hydrous oxide-coated gold electrode in $1.0 \mathrm{~mol} \mathrm{dm} \mathrm{maOH}^{-3} \mathrm{Na} 25^{\circ} \mathrm{C}$; the film was grown in-situ by extended polarization, 90 minutes at $2.3 \mathrm{~V}$ (36)

later by Hoare (29) in terms of adsorbed oxygen). More dramatic, but still quite small, premonolayer oxidation responses were reported later for gold in base by Kirk and coworkers (30). They observed three quasi-reversible transitions (at ca. 0.15, 0.65, and $1.15 \mathrm{~V}(\mathrm{RHE})$, respectively) which they attributed to $\mathrm{Au} / \mathrm{AuOH}_{\text {ads }}$ transitions at different types of surface sites.

Much more enhanced premonolayer oxidation responses may be observed for gold when the electrode is pretreated to generate unusually high coverages of MMS states. The basic principle in such superactivation pretreatment is to insert energy into (or do work on) the sample, or the outer layers of same, in such a manner that after pretreatment some of the inserted energy remains trapped in the sample in the form of MMS states. The superactivation pretreatments (which tend to be severe) used for gold include rapid thermal quenching $(31,32)$ and prolonged cathodization $(33,34)$ (the latter induces hydrogen embrittlement of the metal surface). Rapid thermal quenching is a standard procedure used commercially to produce metastable metals (35). In a very recent work (36) activation involved melting the exposed portion of a short length of gold wire (using a gas torch) to form a molten bead which was allowed to cool rapidly in air. The voltammetric response of such a gold Cooled Bead Electrode (CBE) is shown in Fig. 2. The dominant feature in this case is not the EMS surface response above $1.0 \mathrm{~V}$, but the MMS response below $0.5 \mathrm{~V}$. It is worth noting in this case that the oxidation of superactivated gold commenced (in the positive sweep) at $E<0.0 \mathrm{~V}$ and much of the oxide was reduced (negative sweep) in the same region. Also, since the anodic peak at ca. $0.4 \mathrm{~V}$ appeared in several cycles, the MMS state is not (from a kinetic viewpoint) very labile (indeed total removal of MMS behaviour from a superactivated gold surface can be difficult).

Support for the assumption that the premonolayer responses in the double layer region in Fig. 2 are due to gold (and not some impurity), and that hydrous oxide species are involved as oxidation products of MMS states, is provided by the data summarized in Fig. 3. The multilayer oxide film was produced in this case by severe anodization of an unactivated gold electrode in base. This thick oxide deposit, which is obviously not monolayer-type material, gave rise (as in Fig.2) to large cathodic responses at (and below) $0.0 \mathrm{~V}$. Evidently the reduction products in the negative sweep in Fig. 3 are MMS states of gold (this explains the low potential values). It is also interesting to note that several cathodic peaks appear in this diagram; apparently there are different MMS responses (or states) for gold, distinguished in this case on the basis of their reduction responses. An important point here is that, as discussed later, most of the peak potentials in Fig. 3 coincide with the onset/termination potentials for electrocatalytic processes on gold in base (the same type of correlation applies with gold in acid but the potential values are different mainly due to the involvement of the superNernstian E/pH shift).

If the negative sweep in Fig. 3 is followed by an equivalent positive sweep, few of the corresponding anodic peaks appear (and then only in very muted form), i.e. the high coverage gold MMS states formed on reduction decay rapidly. However, if a gold surface is superactivated by a combination of thermal and cathodic pretreatment, under milder conditions than used when producing the CBE, a total of five well defined anodic peaks may be observed within the double layer region, see Fig. 6 in ref. no. (32). It appears that many of the peaks in Fig. 3 have anodic counterparts, but these do not appear (in enhanced form) in the same cycle. 
However, it is assumed that such active state transitions occur in a quasi-reversible manner at low coverage active sites; this view is supported by the results of Kirk and coworkers (30) and data for the behaviour of silver in base (37).

In summary, MMS gold electrochemistry is quite novel and still in an exploratory stage. It is not clear why so many states are involved (five according to the data in Fig. 3) and what determines the potential values for the transitions in the double layer region. It is assumed that the lower the peak potential the more active the MMS state; apparently the rather severe activation involved in producing the CBE (Fig. 2) favoured the production of an unusually large coverage of a high energy MMS state.

\section{The Nature of the Gold Active Site Species}

Establishing the identity of a low coverage, mobile species at a disordered surface is a particularly challenging task (11); hence the following discussion is rather speculative. According to thermodynamic data (26) the reversible potential for the conversion of bulk gold atoms $\left(\mu^{\circ}=0\right)$ to hydrous gold oxide is $1.457 \mathrm{~V}$ (SHE). A mobile gold atom has little lattice stabilization energy and it may be regarded, to a first approximation, as a gaseous species, $\mu^{\circ}\left(\mathrm{Au}_{\mathrm{g}}\right)=326.4 \mathrm{~kJ}$ $\mathrm{mol}^{-1}$ (38). The conversion of such a species to the hydrous oxide state, at $298 \mathrm{~K}$, is therefore expected to occur (33) at ca. $0.33 \mathrm{~V}$, viz.

$$
\mathrm{Au}_{2} \mathrm{O}_{3}(\mathrm{hydr})+6 \mathrm{H}^{+}+6 \mathrm{e}^{-}=2 \mathrm{Au}_{\mathrm{g}}+3 \mathrm{H}_{2} \mathrm{O}, \mathrm{E}^{\circ}=0.33 \mathrm{~V}(\mathrm{SHE})
$$

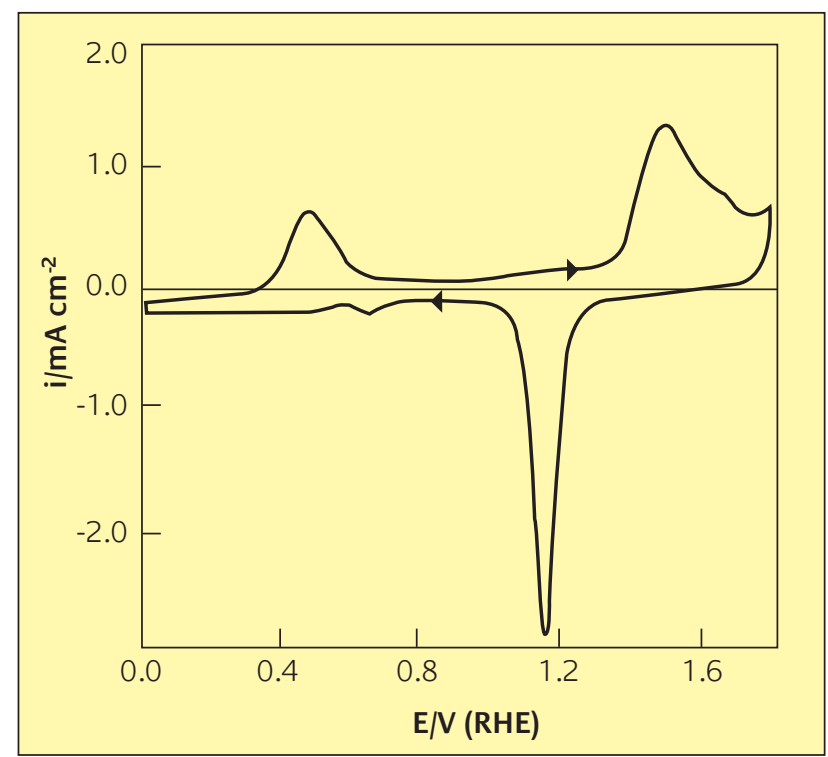

\section{Figure 4:}

Cyclic voltammogram $\left(0.0 \rightarrow 1.8 \mathrm{~V}, 50 \mathrm{mV} \mathrm{s}^{-1}\right)$ for a cathodically activated gold wire electrode in $1.0 \mathrm{~mol} \mathrm{dm}^{-3} \mathrm{H}_{2} \mathrm{SO}_{4}$ at $25^{\circ} \mathrm{C}$; the electrode was pre-cathodized in-situ for 60 minutes at -0.40 V (33)
It is assumed here that the chemical potential of the hydrous oxide species remains constant at $131.67 \mathrm{~kJ} \mathrm{~mol}^{-1}$ (26).

A voltammetric response for cathodically activated gold in acid is shown in Fig. 4. Two anodic responses are evident in the first positive sweep, the regular one due to $\alpha$ oxide formation above $1.35 \mathrm{~V}$ and the active state response due to $\beta$ oxide formation commencing at ca. $0.3 \mathrm{~V}$; according to such data the highly active surface state of gold apparently involves mobile atoms which have very little lattice stabilization energy. A similar onset potential was observed (31) for the active state reaction with electrothermally activated gold in acid solution, but the behaviour was more complex. A range of premonolayer peaks (similar to the case of activated gold in base discussed here earlier) was observed. Evidently there are a range of surface active states (or at least active state redox responses). The variation in the nature of the active species may be due to differences in cluster size, cluster adsorption energy, subsurface oxygen content, etc.

The notion of a mobile surface gold atom as an electrocatalytic species is an interesting one. There is obviously a significant gain in entropy associated with mobility, i.e. the T. $\Delta S$ term for the mobile atom may counteract the gain in stabilization energy associated with weak adatom bonding at a fixed surface site.

\section{Unusual Potential/pH Behaviour of Gold}

The surface of a highly activated gold electrode in base tends to undergo initial oxidation, Fig. 2, below $0.0 \mathrm{~V}$ while multilayer hydrous oxide films exhibit a major oxide reduction peak, Fig. 3, in the same region. Such behaviour conflicts with the data for mobile gold atoms summarized here in equation (2). However, as pointed out here earlier, hydrous gold(III) oxides behave as anionic species and their reduction may be summarized (20) by the equation

$$
\left[\mathrm{Au}_{2}(\mathrm{OH})_{9}\right]^{3-}{ }_{\text {ads }}^{-3}+9 \mathrm{H}^{+}+6 \mathrm{e}^{-}=2 \mathrm{Au}^{\circ}+9 \mathrm{H}_{2} \mathrm{O}
$$

Assuming quasi-reversible behaviour, the redox potential for this transition should drop (20] by 1.5 (2.3RT/F) V per unit increase in solution $\mathrm{pH}$ with respect to a $\mathrm{pH}$-independent reference electrode, e.g. SHE, or by 0.5 (2.3 RT/F) V per pH unit with respect to an RHE reference electrode (in terms of the latter, conventional metal/metal oxide electrodes exhibit $\mathrm{pH}$-independent reversible potential values). In terms of the RHE scale, the magnitude of the decrease on changing from acid to base (assuming $\Delta \mathrm{pH}=13$ ) at $298 \mathrm{~K}$ is ca. $0.38 \mathrm{~V}$ : thus the $\mathrm{Au}^{*} / \mathrm{AuO}_{3}$ (hydr.) transition which appears at ca. $0.33 \mathrm{~V}$ in acid should occur (as observed, Fig. 2) at ca. $-0.05 \mathrm{~V}$ in base. More detailed discussion of this type of behaviour, which is 
not confined to gold, is given (20) elsewhere.

The above type of potential/pH behaviour is referred to as a super-Nernstian shift. The theory involved was developed originally (39) to explain why thin hydrous gold oxide films undergo reduction at a significantly lower potential in base (ca. $0.65 \mathrm{~V}$ ) than in acid (ca. $1.05 \mathrm{~V}$ ); more complex, multifeatured, reduction responses are observed with thicker oxide films. However, super-Nernstian behaviour is possibly more important with regard to the electrocatalytic behaviour of gold. In some cases, e.g. hydrazine oxidation (24), the electrocatalytic reaction commences at a significantly lower potential in base than in acid (the same type of interfacial mediator is assumed to be involved in both solutions). This effect, combined with greater oxide mediator coverage in base, plus the lower tendency of gold surfaces generally to become deactivated by adsorbed species, seems to be the reason why gold in base is often the preferred system for use as a pulsed amperometric (or electrocatalytic) detector system (40) in HPLC analysis.

The redox transition involved in the case of mildly activated gold in base at ca. $0.15 \mathrm{~V}$ is assumed (27) to be based on an $\mathrm{Au} / \mathrm{Au}^{+}$ads (hydr) transition. As the oxidized state in this case is cationic, rather than anionic, the opposite (or sub-Nernstian) type of potential/pH behaviour is expected, i.e. an increase in reversible potential with increasing solution $\mathrm{pH}$ (by $59 \mathrm{mV} / \mathrm{pH}$ unit, in terms of the RHE scale, at $25^{\circ} \mathrm{C}$ ). There is some electrocatalytic data to support this viewpoint (41); an important point is that the transition in question, which occurs at ca. $0.15 \mathrm{~V}$ in base, should (in terms of the above view) occur at ca. $0.15-13(0.059)=-0.62 \mathrm{~V}$ in acid The conclusion is that the $\mathrm{Au}(0) / \mathrm{Au}(\mathrm{I})$ transition occurs at far too low a value (well into the hydrogen gas evolution region) in solutions of low pH; mediation by the couple in question is relevant only to electrocatalysis at gold in base.

\section{Some Electrochemical Correlations}

From an electrocatalytic viewpoint, the vital species at the interface are the active sites which are often regarded as unidentified (42) but in the present case are assumed to consist of low coordination surface gold atoms and their oxidation products. Such species, whose coverage is usually extremely low ( $<1 \%$ of a monolayer), are very difficult to investigate but the following electrochemical procedures have provided useful, though indirect, data as to their nature, viz.

(i) Superactivation: As is clear from Fig. 2 and Fig. 4, it is possible, by appropriate electrode pretreatment, to temporarily raise the occupancy of high energy surface states and monitor the oxidation behaviour of the atoms involved. (ii) Multilayer hydrous oxide reduction: In this case the oxidized forms of the active site species are produced at a high coverage and their reduction behaviour investigated.

(iii) Electrocatalytic behaviour: This is readily monitored by cyclic voltammetry and, by investigating a wide range of reactions (under different conditions, e.g. with regard to $\mathrm{pH})$, trends become evident.

Ideally, all three approaches should provide complementary data and this is generally the case for gold, e.g. the data in Fig. 3 here supports the conclusion based on Fig. 2, namely that a gold/hydrous oxide transition may occur in base at the extraordinary low value of ca. $0.0 \mathrm{~V}$. Active site atoms on gold may apparently be fixed or mobile species and there seem to be variety of distinguishable states. Two important properties of the site species are (a) they are high energy, thermodynamically unstable, entities and (b) they undergo (in the course of electrocatalytic reactions) rapid, quasireversible, redox transitions. Apparently the different states at a given interface can exist independently; this assumption is based on the observation $(36,43)$ that in the case of a multicomponent hydrous oxide film the reduction response

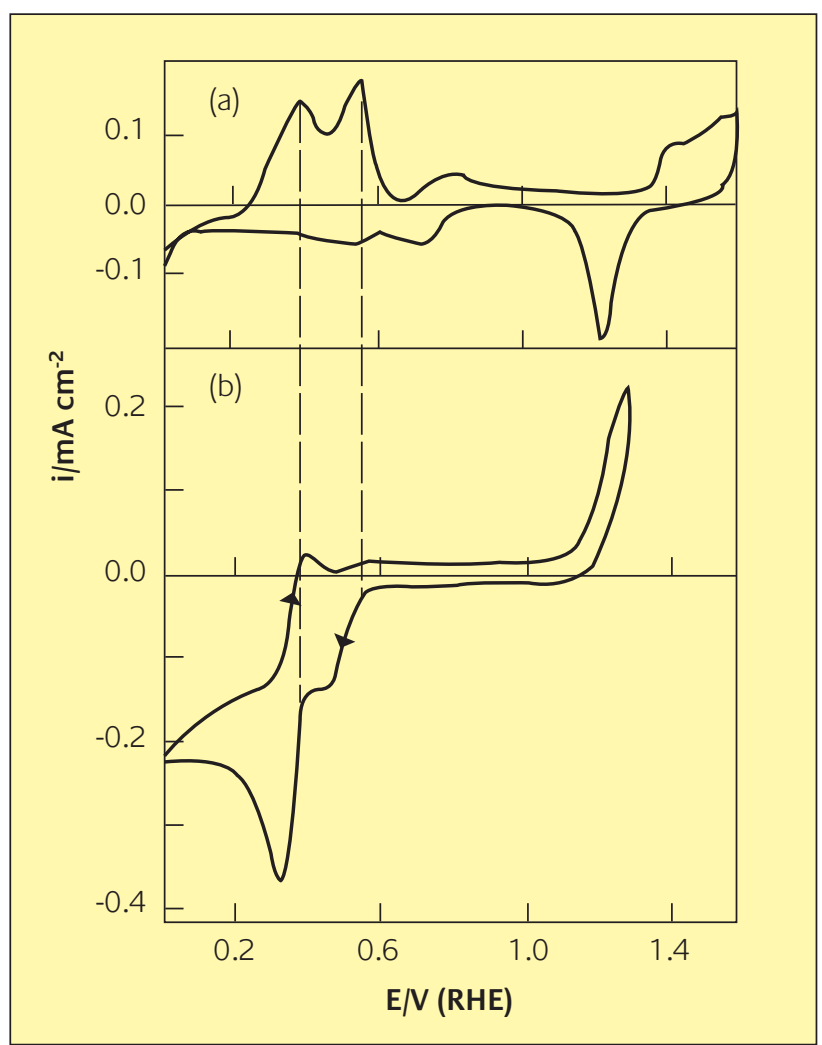

Figure 5:

(a) Cyclic voltammogram $\left(0.0 \rightarrow 1.60 \mathrm{~V}, 50 \mathrm{mV} \mathrm{s}^{-1}\right)$ for a thermally activated $\left(905^{\circ} \mathrm{C}\right.$ for 20 seconds in an argon atmosphere) gold wire electrode (31) in $1.0 \mathrm{~mol} \mathrm{dm}^{-3} \mathrm{H}_{2} \mathrm{SO}_{4}$ at $18^{\circ} \mathrm{C}$;

(b) cyclic voltammogram $\left(0.0 \rightarrow 1.30 \mathrm{~V}, 50 \mathrm{mV} \mathrm{s}^{-1}\right)$ for an unactivated gold wire electrode in $1.0 \mathrm{~mol} \mathrm{dm}^{-3} \mathrm{H}_{2} \mathrm{SO}_{4}+0.001 \mathrm{~mol} \mathrm{dm}^{-3} \mathrm{JGB}$ at $60^{\circ} \mathrm{C}(44)$ 
for a given component seems to be independent of the presence or absence of the other oxide components.

An interesting correlation between the premonolayer oxidation response of a highly activated gold electrode and an electrocatalytic response observed for an unactivated gold electrode, both in acid solution, is shown in Fig. 5 . In the first case, Fig. 5(a), marked anodic peaks were observed within the double layer region with maxima at ca. 0.45 and ca. $0.55 \mathrm{~V}$, respectively. In the negative sweep in Fig. 5(b) two cathodic waves are evident for the reduction of JCB (the latter, an organic dye, is a diazo compound, $\mathrm{C}_{30} \mathrm{H}_{31} \mathrm{ClN}_{6}$, which is often used as an additive in copper Damascene plating baths (44) now employed in the microelectronics industry). The dashed lines in Fig. 5 show that despite the major difference in the surface states involved the oxide formation peak potentials in (a) coincide rather well with the onset potentials for electrocatalytic reduction in (b); evidently the same basic types of active state transitions are involved at both interfaces (similar correlations were discussed recently for silver (37) in base).

A further interesting feature in Fig. 5(b) is the anodic response commencing and terminating at ca. $1.1 \mathrm{~V}$. This response is not due to monolayer oxide behaviour, and is therefore attributed to a JGB electrocatalytic oxidation reaction. As pointed out earlier, there is both a multilayer hydrous oxide reduction (45) and an electrocatalytic oxidation (for some organic acids (5)) response with gold in acid at ca. $1.05 \mathrm{~V}$.

\section{The IHOAM Model of Electrocatalysis}

There are two well known mechanisms used, e.g. in the fuel cell area, to explain the electrocatalytic behaviour of noble metals and their alloys. The first, activated chemisorption, is not very relevant to very weakly chemisorbing EMS gold. However, active site (MMS) gold atoms are quite different. Reactive solution species such as aldehydes or hydrazine are assumed to interact chemically with either the reduced or oxidized form of the active site couple but few details of such interactions are known. The reactivity of the incoming molecule may well be modified, e.g. due to complex formation with adatoms, at the active site.

The second mechanism of electrocatalysis is the oxygen transfer route which is used to explain the oxidative removal of $\mathrm{CO}_{\text {ads }}$ from methanol fuel cell anodes. In such a reaction oxygen is assumed to be transferred (from $\mathrm{H}_{2} \mathrm{O}$ to $\mathrm{CO}_{\mathrm{ads}}$ ) via intermediate formation of adsorbed hydroxyl radicals. An obvious weakness of this viewpoint is that it cannot readily account for electrocatalytic reduction processes and, in particular, for the sharp changeover, e.g. in the case of copper in base (46), from aldehyde reduction to aldehyde

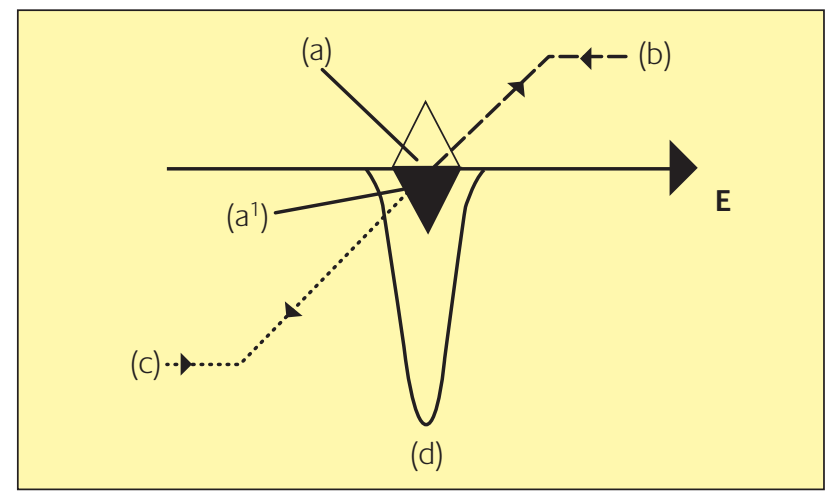

Figure 6:

Schematic representation of the essential features of the IHOAM model of electrocatalysis (46)

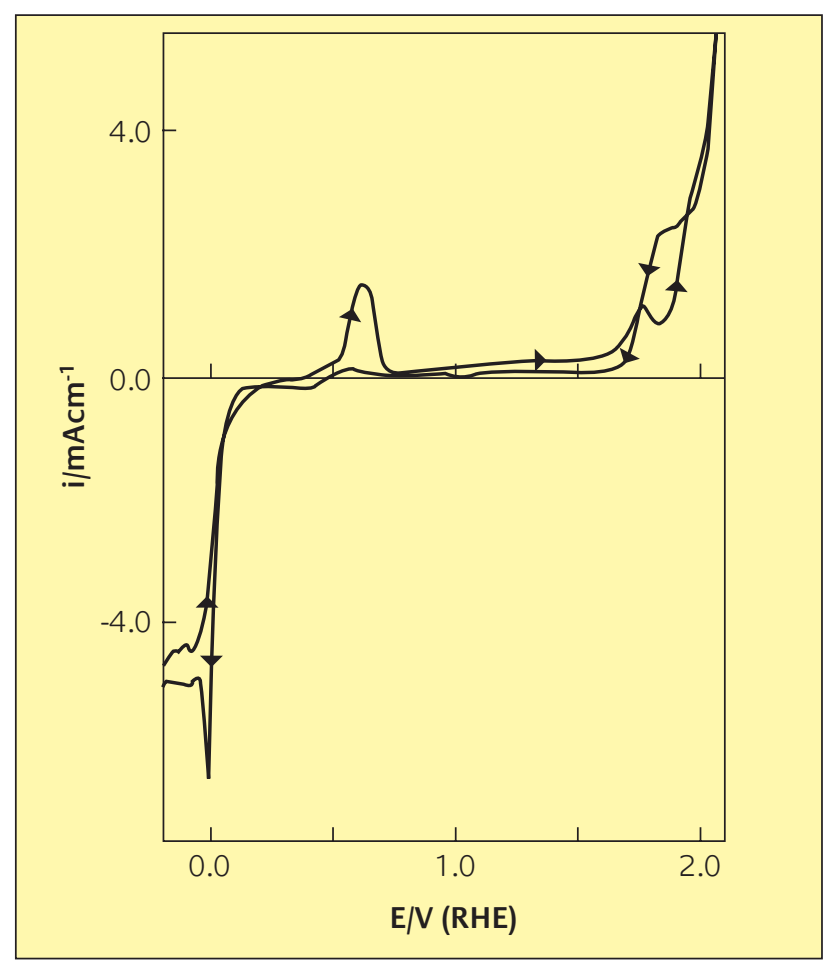

Figure 7:

Cyclic voltammogram $\left(-0.2 \rightarrow 2.1 \mathrm{~V}, 5 \mathrm{mV} \mathrm{s}^{-1}\right)$ for gold in $1.0 \mathrm{~mol} \mathrm{dm}^{-3}$ $\mathrm{NaOH}$ and $0.012 \mathrm{~mol} \mathrm{dm}^{-3} \mathrm{Na}_{2} \mathrm{~S}_{3.7}$ at $35^{\circ} \mathrm{C}$ : the feature of interest is the large cathodic response at ca. $0.0 \mathrm{~V}$

oxidation at a specific potential (well within the double layer region) which coincides with the multilayer hydrous oxide reduction potential.

A novel theory of electrocatalysis, referred to as the Incipient Hydrous Oxide/Adatom Mediator (IHOAM) model, originated from the present author's work largely in the area of hydrous oxide electrochemistry of gold. It was based on the observation (47) that quite often the potential for the onset of electrocatalysis $E_{c}$ (at gold and other metal surfaces) coincides with that for multilayer hydrous oxide reduction. The basic ideas are outlined schematically in Fig. 6. The 
reduction of a pregrown multilayer oxide film yields a large cathodic peak (d) in the negative sweep. This peak is well within the double layer region as the initial product is in the MMS state; the latter, at high coverage, decays rapidly to the lower energy EMS form. Thus, the multilayer oxide reduction process is an irreversible (or one-shot) process, but a remnant of the MMS state usually persist (virtually at an undetectable level) at real metal surfaces. At low coverage the remnant MMS state undergoes a quasi-reversible active atom/hydrous oxide transition (peaks a and $\mathrm{a}^{\prime}$ ), the hydrous oxide species and active atoms acting as mediators for the oxidation (at $\mathrm{E}$ $>E_{c}$, curve b) and reduction (at $E<E_{c}$, curve $c$ ), respectively, of dissolved reactants.

Virtually all the electrocatalytic reactions on gold in aqueous media occur (as expected in terms of the active surface state hypothesis) within the double layer region. However, as suggested by the number of reduction peaks in Fig. 3, it seems that there are different types of mediating couples at the interface. These active states may not all be relevant to electrocatalysis, e.g. although there is a hydrous oxide reduction peak at ca. $-0.2 \mathrm{~V}$ in Fig. 3 , there appears to be no electrocatalytic reaction with an onset/termination potential in this region (the energy of this particular active state may be too high for significant occupancy).

According to the IHOAM scheme outlined in Fig. 6, each mediator couple should be capable of triggering oxidation above, and reduction below, $\mathrm{E}_{c}$. This was illustrated earlier for gold in acid (see Fig. 2 in ref no. (5)); hydrazine oxidation occurred dramatically at (and above) ca. $0.85 \mathrm{~V}$ whereas dichromate reduction showed similar behaviour at (and below) the same value. Another interesting example is shown here in Fig. 7. It was pointed out earlier (27) that there is an $\mathrm{Au}(0) / \mathrm{Au}(\mathrm{l})$ interfacial mediator system for gold in base with a transition potential at ca. $0.15 \mathrm{~V}$. At the time support for this assumption was provided by the fact that aldehyde oxidation occurred at (and above) the latter value. Recent work on polysulphide reduction at gold in base, Fig. 7, gave an example of a cathodic counterpart; note the dramatic increase in reduction rate (which is not observed with either platinum or glassy carbon electrodes) at ca. $0.15 \mathrm{~V}$ (RHE) (it may be noted also that aldehydes exist in base as gemdiolates, $\mathrm{RCHO}^{-} . \mathrm{OH}$, which, along with polysulphide, $\mathrm{S}_{x}{ }^{2-}$, are anionic species).

It is interesting to note that in some instances, as illustrated here for polysulphide reduction, Fig. 7, the interfacial couple acts as a virtual electrical switch, i.e. the electrocatalytic current is switched on and off at a specific potential, the change in rate at the latter being quite dramatic. Such current changes in the mediator transition region are often less dramatic, presumably due to chemical (slow step) complications. It seems quite often that the choice of an interfacial mediator system involved in catalysis

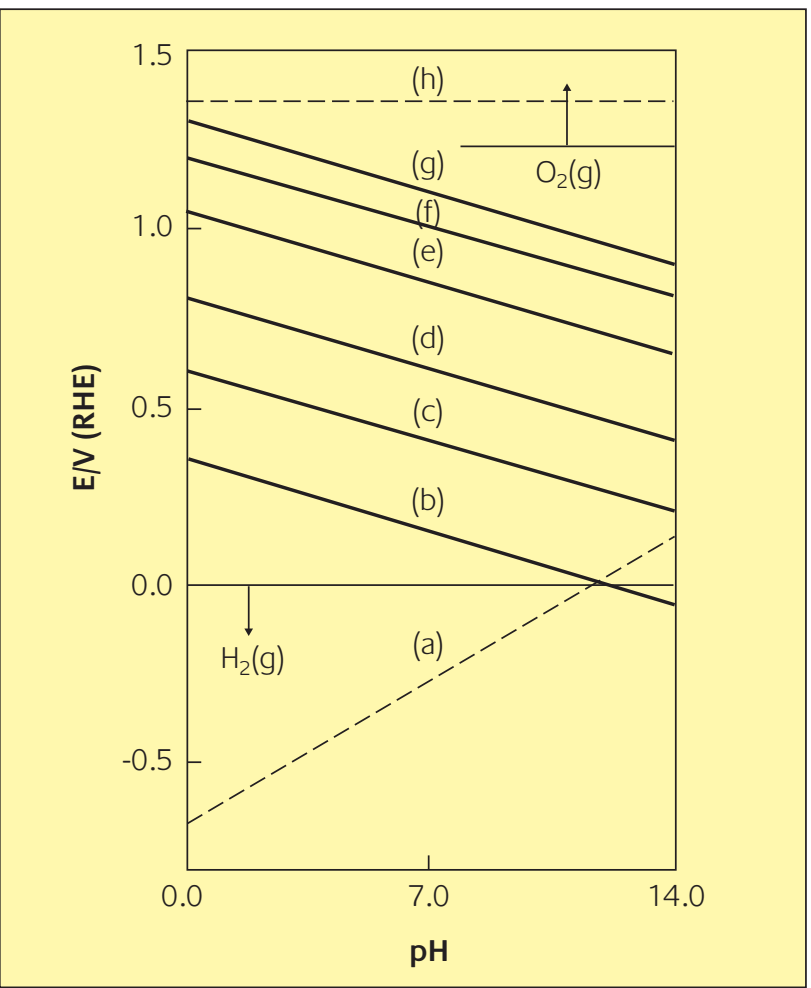

\section{Figure 8:}

Proposed scheme to rationalize the interfacial mediator behaviour of gold in aqueous media at 298K: line (a) is for the $A u(O) / A u(I)$, lines (b) to (g) for $\mathrm{Au}(\mathrm{O}) / \mathrm{Au}(\mathrm{III})$ and line (h) for the $\mathrm{Au}(\mathrm{O}) / \mathrm{Au}_{2} \mathrm{O}_{3}$ transition (all the oxides, apart from $\mathrm{Au}_{2} \mathrm{O}_{3}$, are assumed to be hydrated); this is clearly not a Pourbaix (or equilibrium) diagram

is determined by the reaction that is being catalysed. Usually only one mediator system is involved, although for $\mathrm{NO}_{3}{ }^{-}$ion reduction on copper (48) in base it seems that three distinct mediating couples participate independently (at different potentials) in the reaction.

With regard to its electrocatalytic properties, gold in aqueous media behaves in the same manner as a chemically modified electrode (49). In the latter a relatively inert surface (such as carbon) is modified (to enhance its electrocatalytic activity) by attaching to it suitably active foreign species which may for instance be redox active. A gold electrode, with the EMS atoms functioning as the relatively inert support and the MMS atoms acting as redox mediators, is of very similar character. However, the behaviour of the gold MMS state is complicated as its coverage is not easily controlled and it yields a range of redox transitions or mediator potential values.

A scheme summarizing the behaviour of active interfacial gold mediator systems is given here in Fig. 8. Line (a) describes the behaviour of the $\mathrm{Au}(0) / \mathrm{Au}(\mathrm{I})$ couple which begins to mediate the oxidation of aldehydes and reduction of polysulphide in base at ca. $0.15 \mathrm{~V}$. This mediator system is not effective in acid solution as the transition under such 


\section{Table 1:}

Approximate values for the catalytic mediator, or onset/termination, potentials ( $E_{c}$ ) for gold in aqueous $1.0 \mathrm{~mol} \mathrm{dm}{ }^{-3} \mathrm{H}_{2} \mathrm{SO}_{4}$ at $25^{\circ} \mathrm{C} ;(\mathrm{O}$ ] and (R] denote oxidation and reduction, respectively; unless listed otherwise, the $E_{c}$ values are from ref. no. (5); the values for JGB are from Fig. 5

\begin{tabular}{ll}
\hline$E_{c} / \mathbf{V}$ & $\begin{array}{l}\text { Species whose Catalytic Responses } \\
\text { commence/terminate at the Designated } \\
\text { Potential }\end{array}$ \\
\hline $1.05 \mathrm{~V}$ & $\begin{array}{l}\text { Several organic acids and amino acids (O], JGB (O), } \\
\mathrm{NO}_{2}^{-}(\mathrm{O}], \mathrm{C}_{6} \mathrm{H}_{5} \mathrm{CH}_{2} \mathrm{OH}(\mathrm{O}]\end{array}$ \\
\hline $0.85 \mathrm{~V}$ & $\begin{array}{l}\mathrm{N}_{2} \mathrm{H}_{4}(\mathrm{O}), \mathrm{Cr}_{2} \mathrm{O}_{7}^{2-}(\mathrm{R}], \mathrm{CH}_{3} \mathrm{CHO}(\mathrm{O}), \mathrm{CHOCH} \mathrm{HH}_{2} \mathrm{OH}(\mathrm{O}, \\
\mathrm{C}_{6} \mathrm{H}_{4}\left(\mathrm{NH}_{2}\right)_{2}(\mathrm{O}], \mathrm{CH}_{2} \mathrm{OHC} \equiv \mathrm{CH}(\mathrm{O}]\end{array}$ \\
\hline $0.55 \mathrm{~V}$ & $\mathrm{JGB}\left(\mathrm{R}_{1}\right], \mathrm{O}_{2}(\mathrm{R}), \mathrm{CO}(\mathrm{O}](50)$ \\
\hline $0.35 \mathrm{~V}$ & $\mathrm{JGB}\left(\mathrm{R}_{2}\right], \mathrm{C}_{2} \mathrm{~N}_{3} \mathrm{H}_{2} \mathrm{NO}_{2}(\mathrm{R}], \mathrm{C}_{6} \mathrm{H}_{5} \mathrm{NO}_{2}(\mathrm{R}]$ \\
\hline
\end{tabular}

\section{Table 2:}

Approximate values for the catalytic mediator transition potential for gold in $1.0 \mathrm{~mol} \mathrm{dm} \mathrm{m}^{-3} \mathrm{NaOH}$ at $25^{\circ} \mathrm{C}$; $(O)$ and (R) denote oxidation and reduction; most of the values are from ref. no. (5).

\begin{tabular}{|c|c|}
\hline $\mathrm{Ec} / \mathrm{V}$ & $\begin{array}{l}\text { Species whose Catalytic Responses } \\
\text { commence/terminate at the Designated } \\
\text { Potential }\end{array}$ \\
\hline $0.90 \mathrm{~V}$ & $\mathrm{O}_{2}\left(\mathrm{R}_{1}\right](51), \mathrm{NO}_{2}^{-}(\mathrm{R}]$ \\
\hline $0.80 \mathrm{~V}$ & $\mathrm{C}_{6} \mathrm{H}_{5} \mathrm{NO}(\mathrm{R}], \mathrm{CO}_{\mathrm{ads}}\left(\mathrm{O}_{3}\right](50)$ \\
\hline $0.60 \mathrm{~V}$ & $\begin{array}{l}\text { Many alcohols }(\mathrm{O}],\left(\mathrm{C}_{6} \mathrm{H}_{5}\right)_{2} \mathrm{~N}_{2}(\mathrm{R}], \mathrm{CO}\left(\mathrm{O}_{2}\right](50) \text {, } \\
\mathrm{NO}(\mathrm{O}]\end{array}$ \\
\hline $0.40 \mathrm{~V}$ & $\mathrm{CCl}_{3} \mathrm{CHO}(\mathrm{O}], \mathrm{N}_{2} \mathrm{H}_{4}(\mathrm{O}], \mathrm{CHO}^{-\mathrm{CHOH}} \cdot \mathrm{COO}^{-}(\mathrm{O}]$ \\
\hline $0.15 \mathrm{~V}$ & $\left.\mathrm{CO}\left(\mathrm{O}_{1}\right](50), \mathrm{HO}_{2}^{-}(\mathrm{R}](51), \mathrm{S}_{\mathrm{x}}^{2-}(\mathrm{R}], \mathrm{HCHO}(\mathrm{O}], \mathrm{BH}_{4}^{-1} \mathrm{O}\right]$ \\
\hline
\end{tabular}

conditions occurs at a very negative potential. The other mediators are assumed to be $\mathrm{Au}(0) / \mathrm{Au}(\mathrm{III})$ couples which exhibit super-Nernstian E/pH behaviour. Hydrazine oxidation on gold commences at ca. $0.4 \mathrm{~V}$ in base and at ca. $0.8 \mathrm{~V}$ in acid (24); this is the basis of line (d). Line (e) is based on the observation that thin hydrous oxide films undergo reduction at ca. $1.05 \mathrm{~V}$ in acid and at ca. $0.65 \mathrm{~V}$ in base (45). The premonolayer oxidation and JGB responses in Fig. 5 indicate the presence of interfacial transitions for gold in acid at ca. 0.4 and $0.55 \mathrm{~V}$, lines (b) and (c). The corresponding values for gold in base are ca. 0.0 and $0.15 \mathrm{~V}$. While no $\mathrm{Au}(\mathrm{III})$-mediated electrocatalytic responses occur in base at the latter potentials, there are two multilayer hydrous oxide peaks in this region, Figs. 2 and 3. Electrocatalytic responses for gold in base also commence at ca. $0.8 \mathrm{~V}$, e.g. COads Oxidation (50), and ca. $0.9 \mathrm{~V}$, e.g. $\mathrm{O}_{2}$ reduction (51); these are the basis of lines (f) and (g). The corresponding transition in strong acid should occur at ca. 1.2 and $1.3 \mathrm{~V}$, respectively. These values are close to the onset of monolayer oxide formation where inhibition is frequently observed.

The synopsis of the mediator (or active site) behaviour of gold given in Fig. 8 is speculative; the main objective here is to rationalize the complexity of the data summarized in the earlier review of the electrocatalytic behaviour (5) of gold. Both the reduced and oxidized states of the mediators are unstable; hence the potential values are ill-defined and should be regarded as being indicative. Complications may arise at intermediate $\mathrm{pH}$ values where the proton and hydroxide ion activities are low and, in buffered solutions, strongly adsorbing anions, e.g. phosphate or borate, are usually present. Ancillary data, in the form of onset/termination potentials for a variety of reactions, are listed here in Tables 1 and 2 in support for the mediator transition values used in Fig. 8 .

Interesting illustrations of the complexity of the active site behaviour of gold is provided by responses reported for oxygen and nitrobenzene reduction and carbon monoxide oxidation. On polycrystalline gold (5) oxygen reduction commences at ca. $0.95 \mathrm{~V}$ in base and ca. $0.5 \mathrm{~V}$ in acid. According to Paliteiro (51), the initial reduction product in base is the hydrogen peroxide ion $\left(\mathrm{HO}_{2}^{-}\right)$; however, there is a further increase in reduction current in the region below 0.2 $\checkmark$ apparently due to the intervention of the $A u(I)$ mediator. Oxygen gas reduction to water is thermodynamically possible below $1.23 \mathrm{~V}$; obviously the choice of reduction route (2electron at ca. $0.95 \mathrm{~V}$ and 4-electron at ca. $0.2 \mathrm{~V}$ ) is dominated by the nature of the interfacial redox mediator.

Carbon monoxide oxidation on gold commences (50) at ca. $0.5 \mathrm{~V}$ in acid and ca. $0.0 \mathrm{~V}$ in base. The behaviour in base is especially interesting; if the electrode is allowed to age (at $-0.1 \mathrm{~V}$ ) in the presence of CO the onset potential increases from ca. 0.0 to ca. $0.5 \mathrm{~V}$. It is evident that a switch in interfacial mediator systems is involved, but it is not clear whether the loss of reactivity at $0.0 \mathrm{~V}$ is due simply to poisoning ( $\mathrm{CO}_{\text {ads }}$ formation) or to gradual decay of the highly active state of some surface gold atoms. Also, after the ageing process, a third anodic response, commencing at ca. $0.8 \mathrm{~V}$, is observed in the positive sweep. This was attributed to $\mathrm{CO}_{\text {ads }}$ oxidation and evidently entailed the intervention of yet another mediator system.

Evidence that the product of reaction at constant potential may be varied by changing the state of the electrode surface has been reported by Nisihara and Shindo (52). They defined two surface states for gold: state A was produced by polishing while state B was produced either by repeated cycling through the monolayer oxide formation/reduction region or by severe cathodization (state $B$ was unstable, it tended to revert to state A). With nitrobenzene in base state $A$ yielded a cathodic wave commencing at ca. -0.6V (SCE), which attained a plateau at ca. $-0.8 \mathrm{~V}(\mathrm{SCE})$, due to the formation of nitrobenzene radical anions, $\mathrm{C}_{6} \mathrm{H}_{5} \mathrm{NO}_{2}{ }^{-}$. Under the same conditions state $\mathrm{B}$ gave a much larger response as the product in this case was phenylhydroxylamine, $\mathrm{C}_{6} \mathrm{H}_{5} \mathrm{NHOH}$. The latter product could 
also be obtained with state A but only after the intervention of a second wave commencing at ca. - $0.9 \mathrm{~V}$ (SCE). The onset potentials of the two waves in the case of state $A$ are interesting; one is at ca. $0.45 \mathrm{~V}$ (RHE) and the other at ca. $0.15 \mathrm{~V}(\mathrm{RHE})$, i.e. they occur quite close to the last two mediator potentials listed in Table 2. It may well be that the difference between states $A$ and $B$ is a matter of mediator type or activity and not surface contamination.

\section{Future Work}

It is evident that a new era in the surface chemistry of gold has been triggered by the work of Haruta and coworkers (6). This will undoubtedly have implications for electrochemistry which, as outlined here, can make important contributions to understanding the catalytic properties of surfaces. Like most techniques, electrochemistry has strengths and weaknesses but, ideally, both areas, heterogeneous catalysis and electrocatalysis, should advance in a synergistic manner, taking advantage of sophisticated experimental and theoretical approaches.

It is now clear that the surface properties of gold are rather indefinite (or variable); they depend on the state, history or pretreatment of the sample. The challenge is to optimize the surface state for a particular application, bearing in mind that at a practical level this state must be reasonably durable. There are other important variables worth exploring, e.g. addition of a second component, either as a support or in alloy form. This second component may play various roles, e.g. hinder the loss of the surface active state (by retarding sintering processes), increase the oxygen donor properties of the surface or promote more extensive reaction. For example in alkaline fuel cells the performance of gold cathode electrocatalysts may be enhanced by the addition of a low level of a second metal which catalyses the decomposition of peroxide (thereby liberating further oxygen and enhancing the cathodic response). Gold can also be used as a catalyst support; for example, it was claimed recently (53) that the amount of platinum required in acid fuel cell electrodes may be significantly reduced, with virtually no loss of performance, by using carbon electrodes activated by microparticles having a gold-rich core and a platinum-rich outer layer (rather than using pure platinum particles).

For use as electrocatalysts, gold nanoparticles require conducting supports, e.g. carbon (minor traces of oxide may be beneficial); electrochemical techniques for producing carbon-supported gold nanoparticle deposits have already been described (54-56) and it is assumed that the investigation of such deposits will result in renewed interest in the electrochemistry of gold, at both the fundamental and applied level.

\section{Conclusions}

Conventional accounts of the electrochemistry of gold in aqueous media are restricted largely to the responses of the EMS state of the metal; the neglect of the MMS state behaviour seems to have impeded the development of a more comprehensive understanding, especially in the interfacial catalysis area, of the electrochemistry of gold. The electrocatalytic properties of gold are quite complex and an attempt was made here to provide a basis for understanding the sources of this complexity. Application of more sophisticated techniques is desirable; however, caution is advisable as (i) active surfaces are intrinsically disordered, (ii) low coverage mobile species, e.g. adatoms, are not easily imaged (11) and (iii) vital surface reaction intermediates at surface active sites may not give a strong spectroscopic response (42). Studies of the electrochemistry of gold should benefit significantly from (and contribute to) current work on the heterogeneous catalysis of gas phase reactions by supported gold nanoparticles (both areas seem to have more in common than is generally realized). Commercial application of the electrocatalytic properties of gold, e.g. in areas such as fuel cells, electrosynthesis and pollution abatement, are likely to benefit also from new methods for dispersing gold on appropriate supports and producing porous electrode systems; these would reduce the cost and increase the degree of utilization of the metal.

\section{About the Author}

Professor Laurence Declan Burke is a graduate of University College Cork. He was introduced to noble metal electro chemistry as a PhD student by F. A. Lewis at Queens University Belfast in 1961. He returned to Cork in 1965 and has supervised over $30 \mathrm{PhD}$ students in this field. He has also published extensively.

\section{References}

1 R. Woods, in ‘Electroanalytical Chemistry', Vol. 9, ed. A.J. Bard, Marcel Dekker, New York, 1976, pp.1-162

2 D. Pletcher, J. Appl. Electrochem., 1984, 14, 403

3 W. Hauffe and J. Heitbaum, Ber. Bunsenges. Phys. Chem., 1978, 82, 487

4 L.D. Burke and P.F. Nugent, Gold Bull., 1997, 30, 43

5 L.D. Burke and P.F. Nugent, Gold Bull., 1998, 31, 39

6 M. Haruta, N. Yamada, T. Kobayashi and S. lijima, J. Catal., 1989, 115, 301

7 G.C. Bond and D.T. Thompson, Cat. Rev. - Sci. Eng., 1999, 41, 319

8 R.W. Cahn, in 'Rapidly Solidified Alloys', ed. H.H. Liebermann, Marcel Dekker, New York, 1993, p.1

9 R.E. Reed-Hill and R. Abbaschian, 'Physical Metallurgy Principles', 3rd ed., PWS-Kent Publishing Co., Boston, 1992, pp. 227-242 
10 M.J. Jaycock and G.D. Parfitt, 'Chemistry of Interfaces', Ellis Horwood, Chichester, 1981, p. 136

11 G.A. Somorjai, Chem. Rev., 1996, 96, 1223

12 M.S. Spencer, Nature, 1986, 323, 685

13 H.S. Taylor, Proc. Roy. Soc. Lond. A, 1925, 108, 105

14 A. Henglein, Ber. Bunsenges, Phys. Chem., 1997, 101, 1562

15 K. Besocke and H. Wagner, Phys. Rev. B, 1973, 8, 4597

16 J. Desilvestro and M.J. Weaver, J. Electroanal. Chem., 1986, 209, 377

17 E. R. Savinova, P. Kraft, B. Pettinger and K. Doblhofer, J. Electroanal. Chem., 1997, 430, 47

18 S. Härtinger, B. Pettinger and K. Doblhofer, J. Electroanal. Chem., 1995, 397, 335

19 G. Milazzo and S. Caroli, 'Tables of Standard Electrode Potentials', John Wiley, New York, 1978, p.229

20 L.D. Burke and M.E.G. Lyons, in 'Modern Aspects of Electrochemistry', No. 18, ed. R.E. White, J. O'M. Bockris and B.E. Conway, Plenum Press, New York, 1986, pp. 169-248

21 M. Jansen and A.V. Mudring, in 'Cold, Progress in Chemistry, Biochemistry and Technology', ed. H. Schmidbaur, John Wiley, New York, 1999, pp. 750-754

22 L.D. Burke and P.F. Nugent, J. Electroanal. Chem., 1998, 444, 19

23 U. Müller, 'Inorganic Structural Chemistry', John Wiley, New York, 1993, p.167

24 L.D. Burke and K.J. O’Dwyer, Electrochim. Acta, 1989, 34, 1659

25 B.E. Conway, in 'Progress in Surface Science', Vol. 49, ed. S.G. Davidson, Elsevier, Oxford, 1995, pp.331-452

26 M. Pourbaix, Atlas of Electrochemical Equilibria in Aqueous Media, Pergamon Press, Oxford, 1966, pp. 399-405

27 L.D. Burke and W.A. O'Leary, J. Appl. Electrochem., 1989, 19, 758

28 K.J. Vetter and D. Berndt, Z. Elektrochem., 1958, 62, 378

29 J.P. Hoare, 'The Electrochemistry of Oxygen', Interscience, New York, 1968, p. 51

30 D.W. Kirk, F.R. Foulkes and W.F. Graydon, J. Electrochem, Soc.,1980, 127, 1069

31 L.D. Burke, L.M. Hurley, V.E. Lodge and M.B. Mooney, J. Solid State Electrochem., 2001, 5, 250

32 L.D. Burke and L.M. Hurley, J. Solid State Electrochem., 2002, 6, 101

33 L.D. Burke and A.P. O'Mullane, J. Solid State Electrochem., 2000, 4, 285
34 L.D. Burke, A.P. O'Mullane, V.E. Lodge and M.B. Mooney, J. Solid State Electrochem., 2001, 5, 319

35 C. Suryanarayana, in 'Materials Science and Technology', Vol. 15, ed. R. Cahn, VCH, Weinheim, 1991, pp. 57-110

36 L.D. Burke, J.M. Moran and P.F. Nugent, J. Solid State Electrochem., 2003, 7, 529

37 A.J. Ahern, L.C. Nagle and L.D. Burke, J. Solid State Electrochem., 2002, 6, 451

38 D.D. Wagman, W.H. Evans, V.B. Parker, I. Halow, S.M. Bailey and R.H. Schumm, 'Selected Values of Chemical Thermodynamic Properties, Technical Note 270-4', National Bureau of Standards, Washington, 1969, p.39

39 L.D. Burke, M.E. Lyons and D.P. Whelan, J. Electroanal. Chem., 1982, 139, 131

40 D.C. Johnson and W.R. LaCourse, Anal. Chem., 1990, 62, 589A

41 L.D. Burke and B.H. Lee, J. Appl. Electrochem., 1992, 22, 48

42 B.C. Gates, 'Catalytic Chemistry', Wiley, New York, 1992, p. 352

43 L.D. Burke and D.T. Buckley, J. Electroanal. Chem., 1996, 405, 101

44 L.D. Burke, A.M. O'Connell and A.P. O’Mullane, J. Appl. Electrochem., 2003, 33, 1125

45 L.D. Burke and M. McRann, J. Electroanal. Chem., 1981, 125, 387.

46 L.D. Burke, J.A. Collins and M.A. Murphy, J. Solid State Electrochem., 1999, 4, 34

47 L.D. Burke and V.J. Cunnane, J. Electroanal. Chem., 1986, 210, 69

48 L.D. Burke, L.M. Kinsella and A.M. O'Connell, Russ. J. Electrochem., in press

49 K. Kinoshita, 'Carbon, Electrochemical and Physicochemical Properties', Wiley, New York, 1988, pp. 239-250

50 H. Kita, H. Nakajima and K. Hayashi, J. Electroanal. Chem., 1985, 190, 141

51 C. Paliteiro, Electrochim. Acta, 1994, 39, 1633

52 C. Nishihara and H. Shindo, J. Electroanal. Chem., 1987, 221, 245

53 Matsushita Electric Industrial Co., Ltd., Japan, Pat. No. JP 2002305001

54 H.Yang, T.H. Lu, R.H. Xue, S.G. Sun and S.P. Chen, J. Appl. Electrochem., 1997, 27, 428

55 M.O. Finot, G.D. Braybrook and M.T. McDermott, J. Electroanal. Chem., 1999, 466, 234

56 M.S. El-Deab and T. Ohsaka, Electrochem. Comms., 2002, 4, 288 